Effect of Chain-Length

and Countersurface on the

Tribochemistry of Bulk Zinc

Polyphosphate Glasses

Journal Article

Author(s):

Crobu, Maura; Rossi, Antonella; Spencer, Nicholas D.

Publication date:

2012-12

Permanent link:

https://doi.org/10.3929/ethz-b-000057679

Rights / license:

In Copyright - Non-Commercial Use Permitted

Originally published in:

Tribology Letters 48(3), https://doi.org/10.1007/s11249-012-0034-5 


\title{
Effect of Chain-Length and Countersurface on the Tribochemistry of Bulk Zinc Polyphosphate Glasses
}

\author{
Maura Crobu $\cdot$ Antonella Rossi $\cdot$ Nicholas D. Spencer
}

Received: 19 June 2012/ Accepted: 17 August 2012/Published online: 4 September 2012

(C) Springer Science+Business Media, LLC 2012

\begin{abstract}
Zinc polyphosphate glasses are considered to be chiefly responsible for the anti-wear efficiency of ZnDTP tribofilms. In this work, the tribochemical properties of amorphous bulk zinc polyphosphates of different chain lengths (ranging from zinc metaphosphate to zinc pyrophosphate) have been investigated. Tribological tests on bulk polyphosphate discs have been carried out using steel and quartz balls as counter-surfaces in a poly- $\alpha$-olefin (PAO) bath at room temperature. The composition in the wear track and on the contact region of the balls has been monitored by small-area and imaging X-ray photoelectron spectroscopy (i-XPS). The XPS analysis revealed that the composition of short-chain-length polyphosphates remained unchanged following tribological stress. Long-chain-length polyphosphates are depolymerized in the wear track as a consequence of a tribochemical reaction. By comparing the results obtained using quartz and steel balls, it could be observed that while the reaction of iron oxide with the polyphosphates certainly plays a role in the depolymerization of the samples under sliding conditions, pressure and shear stress alone and also in the presence of water or oil-oxidized species are able to depolymerize the glass when an inert material is used as counterpart; the composition of the wear track, in this case, is dependent on the applied load. All samples were able to form an adhesive, glassy transfer film on both steel and
\end{abstract}

M. Crobu · A. Rossi · N. D. Spencer ( $\square)$

Laboratory for Surface Science and Technology, Department of Materials, ETH Zurich, HCI H 523, Wolfgang-Pauli-Strasse 10, 8093 Zurich, Switzerland

e-mail: spencer@mat.ethz.ch

A. Rossi

Dipartimento di Scienze Chimiche e Geologiche, Università degli Studi di Cagliari, INSTM Unit- Cittadella Universitaria di Monserrato, 09100 Cagliari, Italy quartz balls, but the short-chain-length polyphosphates showed a lower friction coefficient and wear coefficient. The results suggest a third-body mechanism with the polyphosphates acting as a solid lubricant. Differences in tribological behavior of the different-chain-length polyphosphates are attributable to their mechanical and rheological properties.

Keywords Polyphosphate glasses - Tribochemistry . X-ray photoelectron spectroscopy $\cdot$ XPS

\section{Introduction}

Tribochemistry is an interdisciplinary field concerning the synergistic interaction of both physical and chemical phenomena [1]. This may explain why, despite more than 70 years of extensive research, the mechanisms of film formation and wear protection of the most common and successful class of anti-wear addives, Zinc dialkyldithiophosphates (ZnDTPs), are still incompletely understood [2, 3]. ZnDTP is known to react at the steel interface, forming a tribofilm with thickness, chemical and physical properties that are dependent on conditions such as applied load, temperature, and additive concentration [4-7]. The composition of the tribofilm is heterogeneous, characterized by a pad-like structure and mainly constituted of amorphous zinc and iron polyphosphates [8-10]. Long-chain-length organic and inorganic poly(thio)phosphates are located within the outermost layer, while the bulk of the pads is composed of ortho- and pyrophosphate, also known as short chain-length polyphosphates, with an iron content that increases towards the steel surface, as observed by means of XPS [4] and X-ray absorption near-edge structure (XANES) [11, 12]. The tribochemical reaction path that leads to the formation of such tribofilms is still unclear. At 
room temperature, ZnDTP interacts weakly with the steel surface while, under tribological conditions, the additive reacts to form a thin tribofilm [7]. Longer polyphosphates are formed at higher temperatures [4], while the application of higher pressures leads to the formation of thicker reaction films with shorter chain lengths. A shortening of chainlength has been correlated with rubbing time and applied load $[5,8,13]$.

On the basis of these results, it is clear that tribochemical reactions play the central role in the anti-wear mechanism of ZnDTP [14]. In order to design new molecules as effective as ZnDTP but with reduced metal, P and S content, as required by recent environmental regulations, a better understanding of the correlation between the tribochemical reactions of film formation, the friction processes and the wear mechanism is necessary. For example, it is still not clear if the tribofilm anti-wear efficiency benefits from the presence of short- or long-chain-length polyphosphates. Martin, in 1999, was the first to propose that the reaction between long chain-length polyphosphates and iron oxide, energetically favorable on the basis of the principle of hard and soft acids and bases (HSAB) [15], could also play a role in the anti-wear mechanism [16]. According to his hypothesis, the long-chain-length polyphosphates could limit wear by "digesting" the abrasive iron oxide particles, forming zinc oxide and shorter-chain-length mixed iron/zinc phosphates $[11,17,18]$. It was also proposed that the presence of mixed iron/zinc phosphates at the base of the tribofilm could promote the adhesion of the tribofilm itself to the steel substrate [17]. Nicholls [19] attempted to correlate anti-wear behavior with the degree of phosphate polymerization, via the enhanced mechanical properties at longer chain lengths. However, investigating the effect of pressure on $\mathrm{ZnDTP}$ tribofilm formation, Heuberger [5] came to the opposite conclusion: at higher contact pressures, thicker and tougher films of shorter polyphosphates were observed, which exhibited better wear resistance compared to those formed at lower contact pressures. Moreover, the ZnDTP tribofilm hardness was found to correlate with the mean applied pressure in the rubbing contact, showing the ability of the films to provide appropriate properties over a wide range of imposed conditions [20].

While it is commonly accepted that the anti-wear effectiveness of ZnDTP is correlated with its ability to form a thick polyphosphate film, very little is known about the properties of bulk polyphosphate glasses. Testing the behavior of pure zinc orthophosphate powder as an antiwear additive, Gauvin made a first step in this direction [21]. We subsequently developed the first protocol for synthesizing and testing amorphous bulk polyphosphate glasses [13], and investigated the tribochemical behavior of amorphous bulk zinc metaphosphate: the tribochemical reaction between zinc metaphosphate and iron oxide was found to cause the depolymerization of the glass within the wear track. A glassy transfer film, capable of reducing friction and preventing wear, was also detected on the contact area of steel ball countersurface [13]. The characterization of different-chain-length zinc polyphosphates, ranging from orthophosphate to metaphosphate, was also reported, together with a strategy for chain-length identification by means of XPS and time-of-flight secondary-ion mass spectroscopy (ToF-SIMS) [22]. The intensity ratio between the bridging oxygen signal (BO) and the non-bridging (NBO) has been commonly used in order to estimate the polyphosphate chain-length from the XPS data [4, 5, 7, 13, 22-24]. However, tribological samples generally exhibit a very heterogeneous composition and the presence of overlapping species can affect the measured $\mathrm{BO} / \mathrm{NBO}$ value. In order to overcome this problem, the combined use of the $\mathrm{BO} / \mathrm{NBO}$ intensity ratio, the $\mathrm{Zn} 3 \mathrm{~s}-\mathrm{P} 2 \mathrm{p}_{3 / 2}$ binding energy (BE) difference, and the modified Auger parameter was proposed, in order to distinguish between different-chain-length samples unambiguously [22].

This approach has been applied in the present study, in order to investigate the effect of composition on the tribochemical behavior of bulk zinc polyphosphate glasses. This investigation continues our fundamental research into the tribochemistry of bulk polyphosphate glasses by considering two important variables:

- The effect of chain-length and

- The effect of the counterpart material

These results will address some important questions about ZnDTP tribofilms:

- Is the tribochemical reaction between iron oxide and zinc polyphosphate enhancing the anti-wear efficiency of the additive?

- Does the tribofilm anti-wear efficiency benefit from the presence of short-or long-chain-length polyphosphates?

\section{Experimental}

\subsection{Synthesis and Characterization of the Glasses}

The details for the preparation of the glasses, their compositions and characterization are described in [22]. Three different compositions have been investigated in this work: zinc metaphosphate ([O]/[P] of 3), zinc polyphosphate ${ }_{1.5}$ $([\mathrm{O}] /[\mathrm{P}]$ of 3.167) and zinc pyrophosphate $([\mathrm{O}] /[\mathrm{P}]$ of 3.5). Different composition polyphosphates were synthesized starting from stoichiometric mixtures of ammonium dihydrogen phosphate and zinc oxide. The reagents in powder form were melted in alumina crucibles at $1473 \mathrm{~K}$ and then quenched in a copper tray that had been previously cooled 
to $253 \mathrm{~K}$. After quenching, the samples were annealed at $623 \mathrm{~K}$ for $8 \mathrm{~h}$, in order to reduce internal stresses.

\subsection{Mechanical Polishing}

Prior to the tribological tests, the samples were mechanically polished. Grinding was performed by means of P320, P600, P1200, and P2400 silicon carbide paper (Struers $\mathrm{GmbH}$, Birmensdorf, Switzerland). The polishing was then performed using diamond paste $(3$ and $1 \mu \mathrm{m})$ on polishing cloths (Struers GmbH, Birmensdorf, Switzerland). The surface roughness $(\mathrm{Ra})$ was measured by AFM and found to be $4.0 \pm 0.2 \mathrm{~nm}$. Ethanol was always used as a polishing lubricant, in order to dissipate the heat produced by friction and to prevent chemical changes at the surface. The samples were then kept in an ultrasonic bath in ethanol for $10 \mathrm{~min}$ prior to testing.

\subsection{Tribological Tests}

The tribological tests were carried out by means of a CETR UMT-2 tribometer in a ball-on-disk configuration. The load cell had a maximum load of $20 \mathrm{~N}$ and a resolution of $1 \mathrm{mN}$ in two axes: normal load and friction force. 100Cr6 steel balls and quartz (optical fused quartz, Spectrosil ${ }^{\circledR}$ 2000) balls with a diameter of $6 \mathrm{~mm}$ provided the counter-surfaces against the zinc polyphosphates polished discs. The roughness of the balls before the tests was characterized by means of a white-light profilometer (Sensofar Plu Neox. Sensofar-Tech SL., Terrassa, Spain) and was found to be $0.277 \pm 0.005 \mu \mathrm{m}$ for the steel balls and $0.037 \pm$ $0.005 \mu \mathrm{m}$ for the quartz balls. The tests were performed at room temperature in pure poly- $\alpha$-olefin (PAO, Durasyn ${ }^{\circledR}$ 166, Tunap Industrie $\mathrm{GmbH} \& \mathrm{Co}$., Mississauga, Canada) at two different loads, 5 and $7 \mathrm{~N}$, with a constant sliding speed of $30 \mathrm{~mm} / \mathrm{min}$. Lubricated, rather than dry conditions were chosen, so as to mimic the rheological and thermal environment of a lubricated metal-metal contact. Four concentric wear tracks, separated from each other by $75 \mu \mathrm{m}$, were obtained on each disc. In our previous work [13], it was observed that a glassy transfer film, able to affect friction and wear, is formed on the ball during the test: in order to have reproducible results a new ball (without running-in) was used at the beginning of each test.

Before the analysis, balls and discs were cleaned in an ultrasonic bath for $10 \mathrm{~min}$ in $n$-hexane and gently wiped with a tissue paper. The tribostressed balls and discs were then examined with the aid of a light microscope.

\subsection{XPS and Imaging-XPS}

XPS spectra were acquired with a PHI Quantera SXM spectrometer (ULVAC-PHI, Chanhassen, MN, USA) equipped with an $\mathrm{AlK} \alpha$ monochromatic source, whose beam size ranges from 5 to $200^{\circ} \mu \mathrm{m}$. A Gauze input lens collects the photoelectrons at an emission angle of $45^{\circ}$ and directs them through the high-resolution spherical capacitor analyzer to the 32-channel detector system. The spectrometer is also equipped with a low-voltage argon ion gun and a sample neutralizer for charge compensation. The linearity of the binding energy scale was checked using sputter-cleaned gold, silver and copper as reference materials according to ISO15472:2001. The accuracy was found to be $\pm 0.1 \mathrm{eV}$. The residual pressure was below $5 \times 10^{-7} \mathrm{~Pa}$ during each acquisition. XPS binding energies, intensity ratios and other calculated values are reported in this work as means of three or more independent samples, along with their corresponding standard deviations.

Survey spectra were acquired in fixed analyzer transmission (FAT) mode using a pass energy (PE) of $280 \mathrm{eV}$, while the high-resolution spectra were collected with a PE of $26 \mathrm{eV}$; the full width at half maximum of the peak height, FWHM, of the silver Ag3 $\mathrm{d}_{5 / 2}$ signal for high-resolution spectra was $0.62 \mathrm{eV}$. Both survey and high-resolution spectra were collected using a beam diameter of $100 \mu \mathrm{m}$. X-ray-excited, secondary-electron images (SXI) were used in order to visualize the topography and thus to facilitate the collection of small-area XPS spectra from the features present on the sample. When analyzing the phosphate glass discs and the quartz balls, the electron neutralizer was used, in order to compensate for sample charging. The spectra were further corrected with reference to adventitious aliphatic carbon at $285.0 \mathrm{eV}$.

Imaging X-ray photoelectron spectroscopy (i-XPS) was performed with a beam size of $20 \mu \mathrm{m}$ and a PE of $140 \mathrm{eV}$ in snapshot mode; under these conditions, the spectra were acquired over a BE range of $15.5 \mathrm{eV}$. The area of the maps was $600 \times 600 \mu \mathrm{m}^{2}$ and required $1-2 \mathrm{~h}$ of acquisition per map. Maps of the carbon signal, C1s, were acquired in order to exclude the possibility of localized sample charging.

The spectra were processed with CasaXPS software (version 2.3.15, Casa Software Ltd, Wilmslow, Cheshire, UK). The background subtraction was performed using the Shirley-Sherwood iterative method. The product of Gaussian and Lorentzian functions was used for the curvefittings. The maps were processed by means of Multi$\mathrm{Pak}^{\mathrm{TM}}$ software (version 8.1c, ULVAC-PHI, Chanhassen, MN, USA).

Quantitative analysis was performed using sensitivity factors measured with the same experimental setup on samples prepared with the same protocol and reported in [22], together with a full characterization of the samples. A correction for the contamination layer was applied as well, using the method proposed by Smith [25]. 
Fig. 1 Coefficient of friction (COF) and wear coefficient measured on the steel ball after sliding on bulk zinc

polyphosphate discs of different chain lengths in a pure PAO bath at room temperature with a sliding speed of $0.5 \mathrm{~mm} / \mathrm{s}$ and normal load of 5 and $7 \mathrm{~N}$
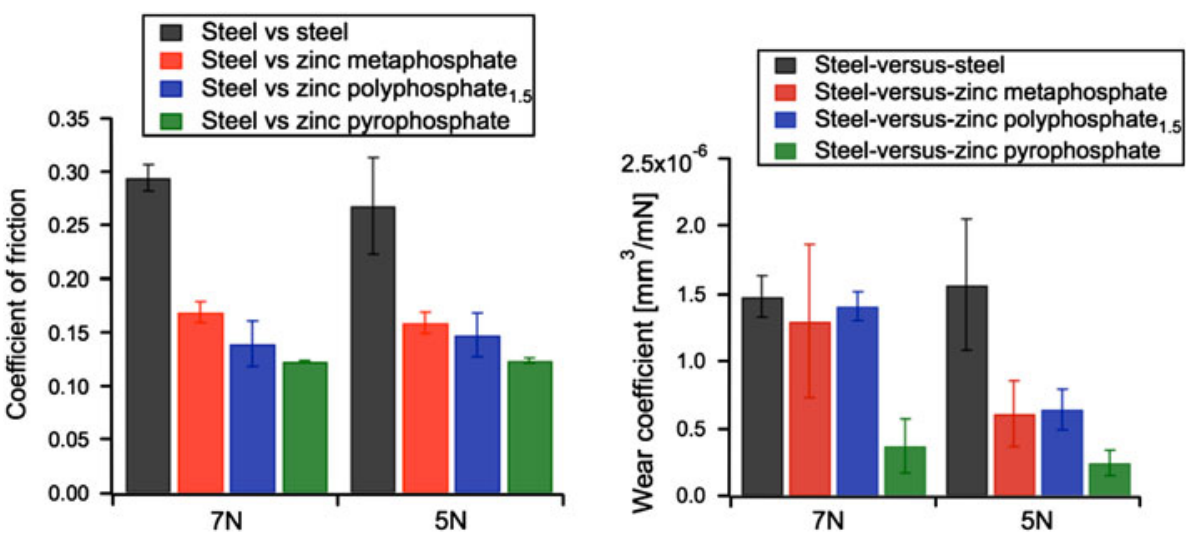

\section{Results}

\subsection{Steel-Versus-Zinc Polyphosphate Tribo-Pair}

\subsubsection{Steel-Versus-Zinc Polyphosphate Tribo-Pair: Tribological Tests}

The synthesis and characterization of the glasses has been reported in [22]. Three different compositions have been investigated in this work: zinc metaphosphate $([\mathrm{O}] /[\mathrm{P}]$ of
3), zinc polyphosphate ${ }_{1.5}([\mathrm{O}] /[\mathrm{P}]$ of 3.167$)$ and zinc pyrophosphate $([\mathrm{O}] /[\mathrm{P}]$ of 3.5$)$.

The results for tribological tests performed by sliding a steel ball against zinc polyphosphates of different composition are shown in Fig. 1. A small running-in effect was observed in the first $500 \mathrm{~mm}$ and after that the coefficient of friction appears to remain constant with sliding distance. For this reason, the average coefficient of friction has been calculated considering only the last $2,000 \mathrm{~mm}$ of the test. As shown in Fig. 1, the coefficient of friction is constant
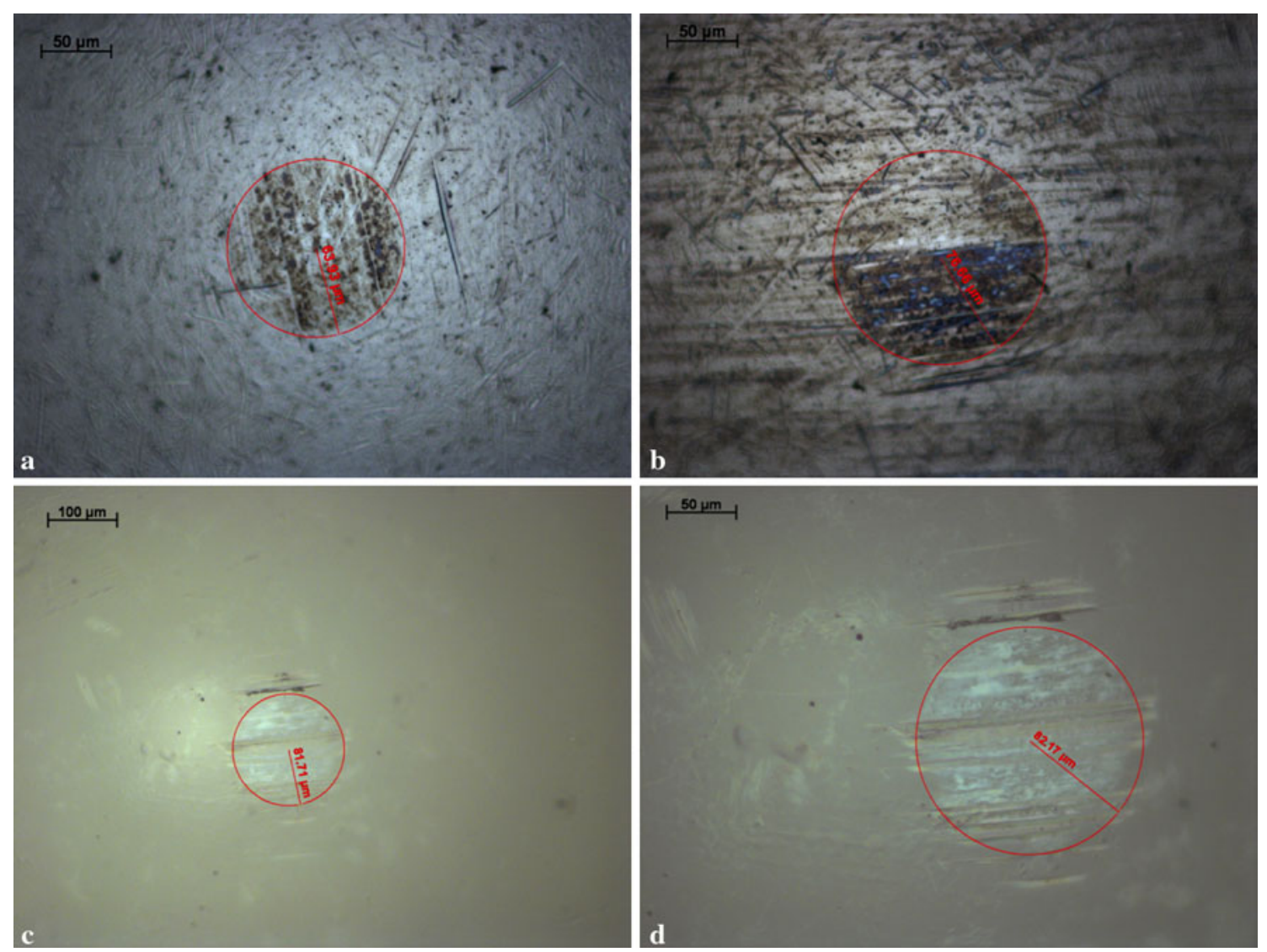

Fig. 2 Light microscope images of the contact area on the ball for steel-versus-zinc pyrophosphate $(\mathbf{a}, \mathbf{b})$ and quartz-versus-zinc pyrophosphate $(\mathbf{c}, \mathbf{d})$ at $5 \mathrm{~N}(\mathbf{a}, \mathbf{c})$ and $7 \mathrm{~N}(\mathbf{b}, \mathbf{d})$ normal load 
Fig. 3 High-resolution $\mathrm{XP}$-spectra outside and inside the tribotrack on the zinc pyrophosphate disc after tribological testing with a steel ball at $5 \mathrm{~N}$ normal load
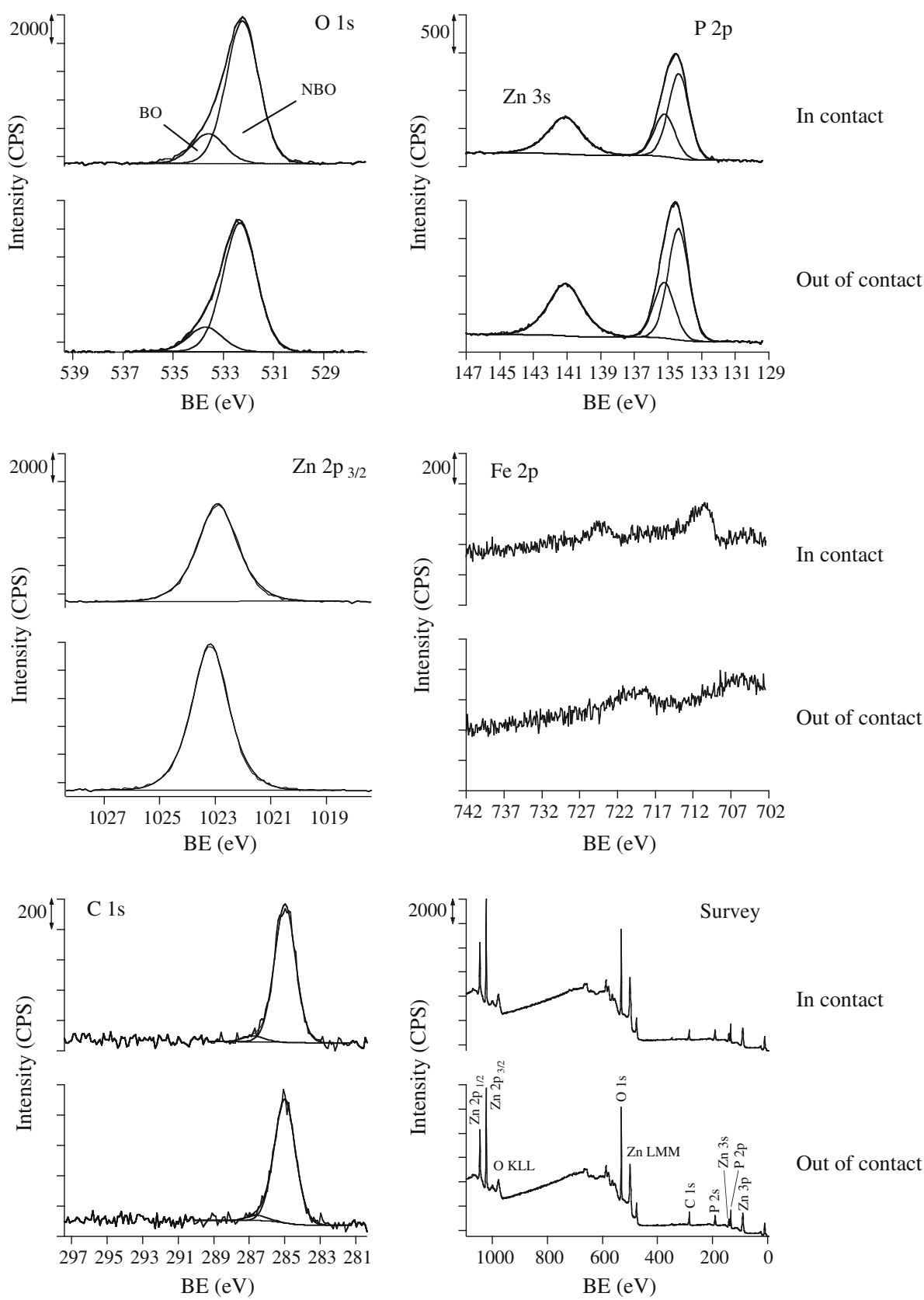

for both tested normal loads ( 5 and $7 \mathrm{~N}$ ), but its value changes with the chain-length of the polyphosphate sample. The coefficient of friction was found to be $0.16 \pm 0.01$ for the steel-versus-zinc metaphosphate, $0.13 \pm 0.01$ for the steel-versus-zinc polyphosphate ${ }_{1.5}$, and $0.12 \pm 0.01$ for the steel-versus-zinc pyrophosphate tribo-pair.

The flattened area on the ball was measured by means of light microscopy (see Fig. 2), and using this value, it was possible to calculate the worn volume for each test. The average values of the wear coefficients for the steel balls, calculated as worn volume per sliding distance and applied load, are reported in Fig. 1. Both coefficient of friction and wear coefficient are lower in the case of the shorter-chain- length polyphosphates. But, unlike the coefficient of friction, the wear coefficient increases with increasing normal load for all compositions.

\subsubsection{Steel-Versus-Polyphosphate Tribo-Pair: XPS Analysis of the Polyphosphate Disc}

The tribostressed polyphosphate discs were analyzed by XPS; high-resolution spectra were acquired in both wear tracks and non-contact areas for comparison. Examples of XPS spectra for a tribostressed zinc pyrophosphate disc are presented in Fig. 3 where the results inside and outside the contact area are directly compared. The O $1 \mathrm{~s}$ signal was 
Table 1 XPS analysis of different-chain-length polyphosphate discs after tribological testing with steel balls

\begin{tabular}{|c|c|c|c|c|c|c|}
\hline & \multicolumn{2}{|c|}{ Zinc metaphosphate } & \multicolumn{2}{|c|}{ Zinc polyphosphate $_{1.5}$} & \multicolumn{2}{|c|}{ Zinc pyrophosphate } \\
\hline & Out-of-contact & Wear track & Out of contact & Wear track & Out of contact & Wear track \\
\hline $\mathrm{BO} / \mathrm{NBO}$ intensity ratio & $0.41 \pm 0.05$ & $0.33 \pm 0.05$ & $0.29 \pm 0.04$ & $0.24 \pm 0.05$ & $0.18 \pm 0.04$ & $0.14 \pm 0.05$ \\
\hline P 2p-Zn 3s BE difference (eV) & $6.32 \pm 0.04$ & $6.48 \pm 0.09$ & $6.51 \pm 0.04$ & $6.65 \pm 0.05$ & $6.73 \pm 0.01$ & $6.80 \pm 0.03$ \\
\hline$[\mathrm{P}] /[\mathrm{Zn}]$ intensity ratio & $2.1 \pm 0.2$ & $2.0 \pm 0.2$ & $1.6 \pm 0.1$ & $1.5 \pm 0.1$ & $1.1 \pm 0.1$ & $1.1 \pm 0.1$ \\
\hline$[\mathrm{O}] /[\mathrm{P}]$ intensity ratio & $3.0 \pm 0.3$ & $3.5 \pm 0.3$ & $3.2 \pm 0.2$ & $3.6 \pm 0.4$ & $3.4 \pm 0.2$ & $3.8 \pm 0.2$ \\
\hline Modified Auger parameter (eV) & $2008.90 \pm 0.07$ & $2009.1_{1} \pm 0.1_{4}$ & $2008.9_{4} \pm 0.1_{2}$ & $2009.0_{9} \pm 0.1_{2}$ & $2009.15 \pm 0.09$ & $2009.27 \pm 0.09$ \\
\hline
\end{tabular}

For each composition the table shows the values obtained analyzing inside the wear track (in contact) and outside the wear track (out of contact). The calculated values (from stoichiometry) for the $[\mathrm{P}] /[\mathrm{Zn}]$ and $[\mathrm{O}] /[\mathrm{P}]$ intensity ratios are 2 and 3 for metaphosphate, 1.5 and 3.2 for polyphosphate, 1 and 3.5 for pyrophosphate, respectively

curve fitted using the two characteristic components of polyphosphate glasses, $\mathrm{BO}$, and NBO. The NBO signal was found at a $\mathrm{BE}$ of $532.3 \mathrm{eV}$, while the distance of the $\mathrm{BO}$ signal from the former varies with the chain-length from $1.6 \mathrm{eV}$ for the metaphosphate to $1.4 \mathrm{eV}$ for the pyrophosphate. The averaged $\mathrm{BO} / \mathrm{NBO}$ intensity ratios for all the tests and compositions are calculated in Table 1. The $\mathrm{BO} /$ $\mathrm{NBO}$ values are lower in the wear track compared to those obtained in the out-of-contact area and this trend is common for the three compositions: from $0.41 \pm 0.05$ in the out-of-contact region to $0.33 \pm 0.05$ in the wear track for zinc metaphosphate, from $0.29 \pm 0.04$ to $0.24 \pm 0.05$ for zinc polyphosphate ${ }_{1.5}$ and from $0.18 \pm 0.04$ to $0.14 \pm 0.05$ for zinc pyrophosphate.

The phosphorus $2 \mathrm{p}$ and zinc $3 \mathrm{~s}$ peaks are detected in this same energy range (Fig. 3). The two components $\mathrm{P} 2 \mathrm{p}_{1 / 2}$ and $\mathrm{P} 2 \mathrm{p}_{3 / 2}$ were constrained to a distance of $0.84 \mathrm{eV}$ in the $\mathrm{BE}$ scale and the area of the $\mathrm{P} 2 \mathrm{p}_{1 / 2}$ was set equal to half of the area of the $\mathrm{P} 2 \mathrm{p}_{3 / 2}$ peak. The $\mathrm{Zn} 3 \mathrm{~s}$ BE value, $141.0 \mathrm{eV}$, was found to be constant with composition while the $\mathrm{P} 2 \mathrm{p}_{3 /}$ 2 peak positions shifts with the composition $[13,22]$. In order to minimize possible uncertainties due to calibration of the sample, the difference between the position of the $\mathrm{Zn}$ 3 s signal and the $\mathrm{P} 2 \mathrm{p}_{3 / 2}$ has been calculated for all tests (Table 1). For all samples, this parameter is higher in the contact region than outside the contact: $\mathrm{P} 2 \mathrm{p}-\mathrm{Zn} 3 \mathrm{~s}$ BE difference increases from $6.32 \pm 0.04 \mathrm{eV}$ in the out-ofcontact region to $6.48 \pm 0.09 \mathrm{eV}$ in the wear track for the case of zinc metaphosphate, from $6.51 \pm 0.04 \mathrm{eV}$ to $6.65 \pm 0.05 \mathrm{eV}$ for the zinc polyphosphate ${ }_{1.5}$, and from $6.73 \pm 0.01 \mathrm{eV}$ to $6.80 \pm 0.03 \mathrm{eV}$ for zinc pyrophosphate. The Auger Zn LMM signal has also been acquired and the values of the modified Auger parameter, $\alpha^{\prime}$, were found to shift towards higher values inside the tribotracks (see Table 1). In agreement with the previous results, the valence band region is also indicating depolymerization of the glass within the tribotrack: the position of the $\mathrm{P} 3 \mathrm{~s}$ peak shifts towards higher BEs from long towards shorter chainlengths [22]. The zinc metaphosphate exhibited the largest shift, $2.5 \mathrm{eV}$, and a spectrum is shown in Fig. 4.
An iron peak was detected in the wear track as a result of transfer of material from the steel ball to the disc. The position and line shape of the carbon peak does not change in the wear track and, as shown in Fig. 3, there are no additional elements in the survey spectrum.

The values of the $[\mathrm{O}] /[\mathrm{P}]$ intensity ratio (Table 1 ) also show higher values within the contact region: [O]/ $[\mathrm{P}]$ increases from $3.0 \pm 0.03$ in the out-of-contact region to $3.5 \pm 0.03$ in the wear track for the case of zinc metaphosphate, from $3.2 \pm 0.2$ to $3.6 \pm 0.4$ for zinc polyphosphate $_{1.5}$, and from $3.4 \pm 0.2$ to $3.8 \pm 0.2$ for zinc pyrophosphate. The $\mathrm{Zn} 2 \mathrm{p}_{3 / 2}$ signal, at $1022.9 \mathrm{eV}$, was also curve fitted and used to calculate the $[\mathrm{P}] /[\mathrm{Zn}]$ intensity ratio; this parameter did not show any relevant change in the tribostressed areas for any of the samples (Table 1).

\subsubsection{Steel-Versus-Zinc Polyphosphate Tribo-Pair: XPS Analysis of the Steel Ball}

The high-resolution spectra and chemical-state maps for a steel ball after a tribological test with a pyrophosphate disc at the normal load of $5 \mathrm{~N}$ are shown in Figs. 5 and 6, while the corresponding optical image is reported in Fig. 2a.

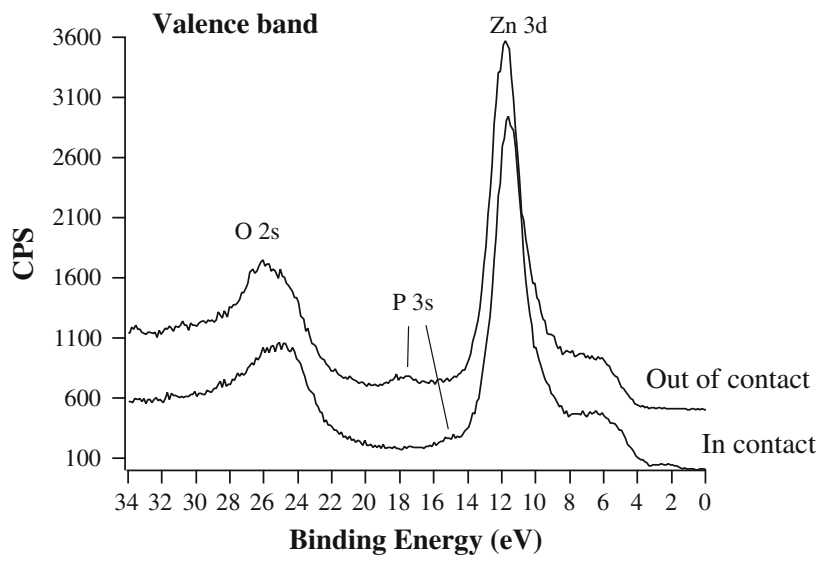

Fig. 4 High-resolution XP spectra of the valence band outside and inside the tribotrack on the zinc metaphosphate disc after tribological testing with a steel ball at $7 \mathrm{~N}$ normal load 
The spectra were acquired in three different areas: in the center of the contact, at the border, and outside of the contact area. Phosphorus $2 p$, zinc $3 s$ and zinc $2 p_{3 / 2}$ signals were measured in the contact area with the same position and line shape characteristic of the zinc polyphosphate samples inside the contact area. Looking at the maps in Fig. 6, the transfer-film area appears with a round shape with a radius of about $60 \mu \mathrm{m}$. This value is consistent with the $64 \mu \mathrm{m}$ measured on the optical image. The high-resolution spectra show that the intensity of the phosphorus and zinc signals is higher at the border than in the center of the area. Moreover, the iron peak is more attenuated at the border than in the center of the area suggesting that the thickness of the transfer film is thicker in that area.

The oxygen $1 \mathrm{~s}$ signal presented three components: a first one at $530.0 \mathrm{eV}$ assigned to oxide species; a second one at $532.2 \mathrm{eV}$ assigned to the NBO in the polyphosphate glass and the hydroxides (these two chemical states are overlapping in the BE scale and cannot be resolved in the spectra); and a third and last one at $534.0 \mathrm{eV}$ assigned to the $\mathrm{BO}$ of the polyphosphate. Using a linear-least-squares routine, the $\mathrm{O} 1 \mathrm{~s}$ map was converted into three maps corresponding to the three chemical states described above (Fig. 6). Further confirming the previous results, the maps show that the BO signal from the polyphosphate glass is present only in the contact area while the oxide signal is detected only outside.

The map of the carbon $1 \mathrm{~s}$ signal was acquired to show that there are no areas of preferential charging on the map. The spectra extracted from the transfer film area were compared with the spectra extracted from the outer area (not shown): the position and line shape of the $\mathrm{C} 1 \mathrm{~s}$ signal were unchanged.

\subsection{Quartz-Versus-Zinc Polyphosphate Tribo-Pair}

\subsubsection{Quartz-Versus-Zinc Polyphosphate Tribo-Pair: XPS Analysis of the Polyphosphate Disc}

The data concerning zinc metaphosphate and zinc pyrophosphate discs after the tribological tests with quartz balls are summarized in Table 2.

For the case of zinc metaphosphate, the $\mathrm{BO} / \mathrm{NBO}$ values were lower in the wear track compared to the values obtained in the out-of-contact area, and this time, in contrast to the steel-versus-polyphosphate tribo-pairs, the value at $5 \mathrm{~N}, 0.37 \pm 0.05$, was different than the value at $7 \mathrm{~N}$ normal load, $0.30 \pm 0.05$. The value of the $\mathrm{BO} / \mathrm{NBO}$ intensity ratio in the case of pyrophosphate, on the other
Fig. 5 Small-area XPS on the contact, border and non-contact areas of the steel ball after tribological testing (at $5 \mathrm{~N}$ normal load) with a zinc pyrophosphate disc
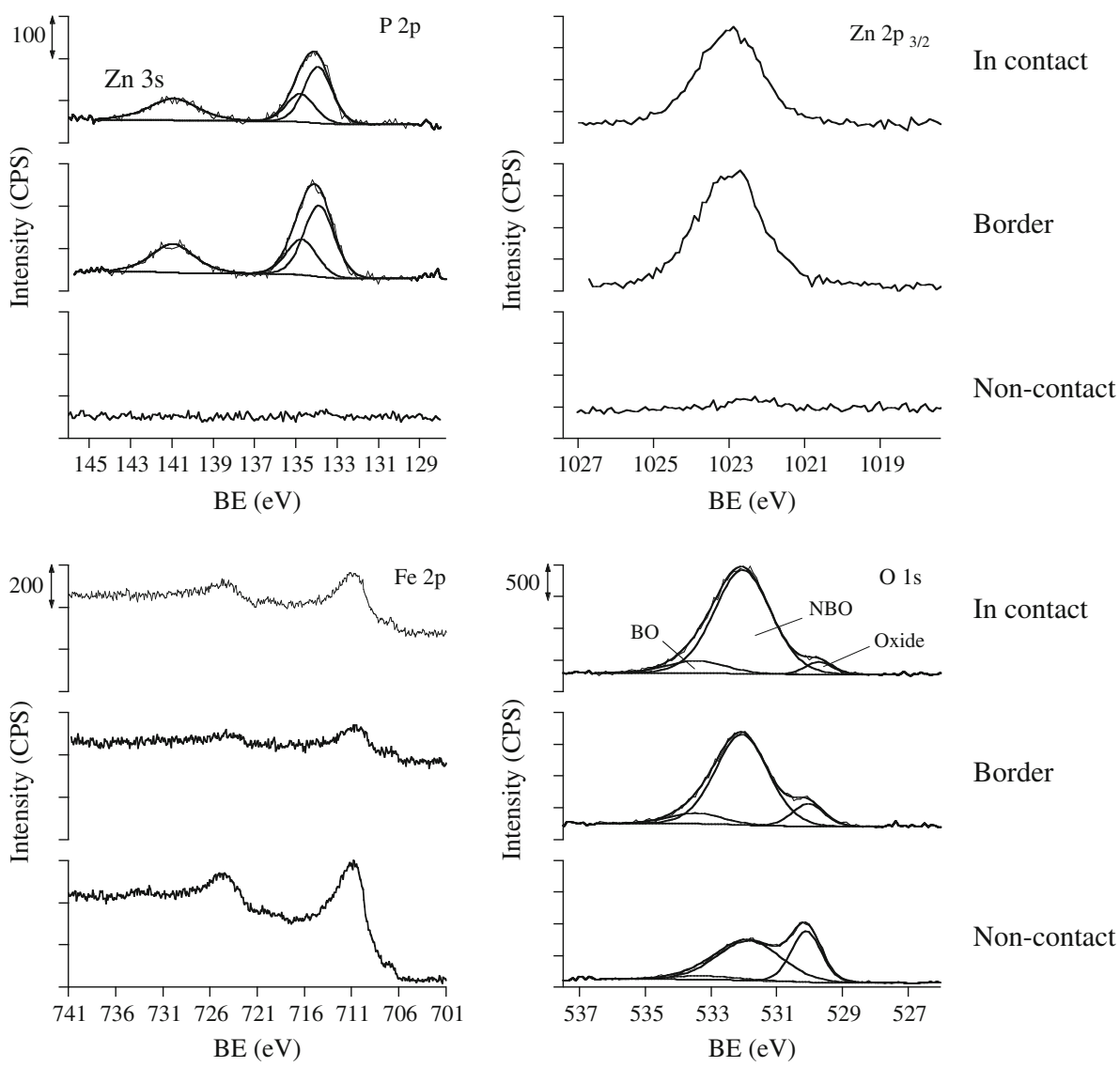
Fig. 6 i-XPS on the contact area of the steel ball after tribological testing (at $5 \mathrm{~N}$ normal load) with a zinc pyrophosphate disc

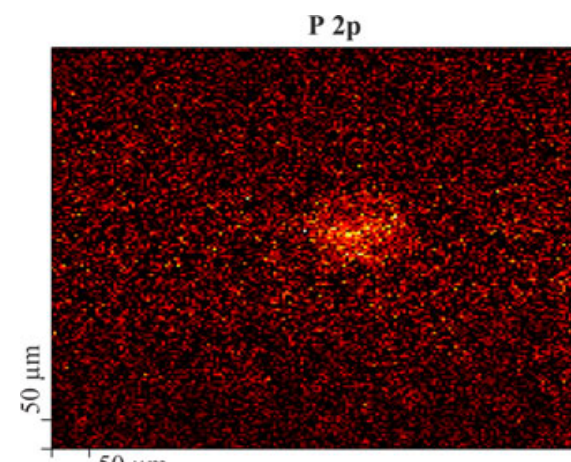

$50 \mu \mathrm{m}$

Fe $2 p_{3 / 2}$

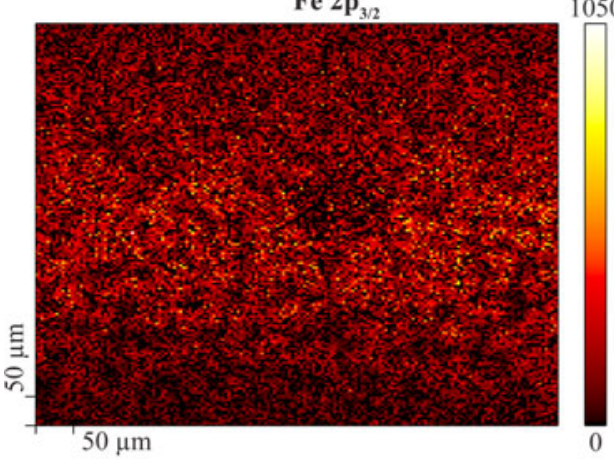

O $1 \mathrm{~s}$

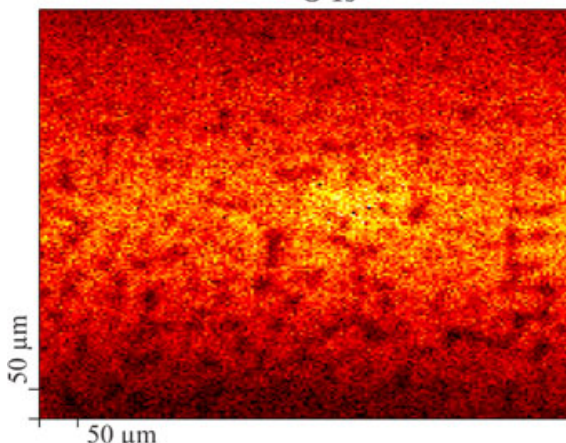

O 1s (NBO)

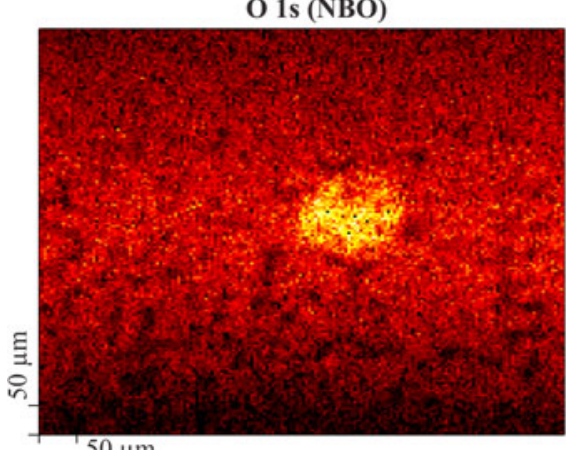

$50 \mu \mathrm{m}$

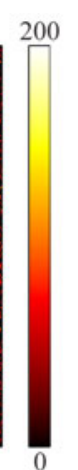

1050

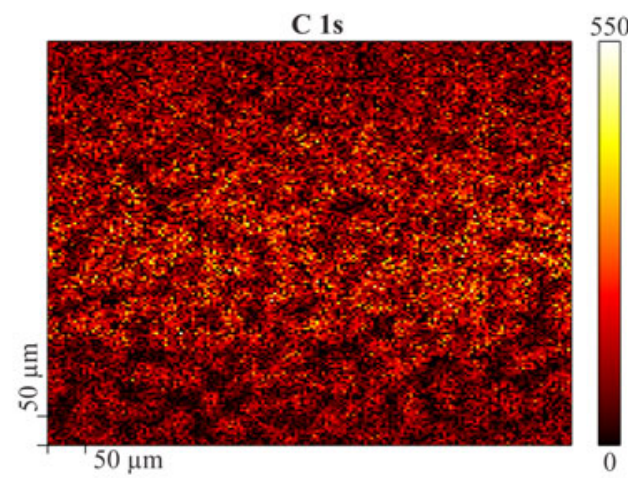

1000

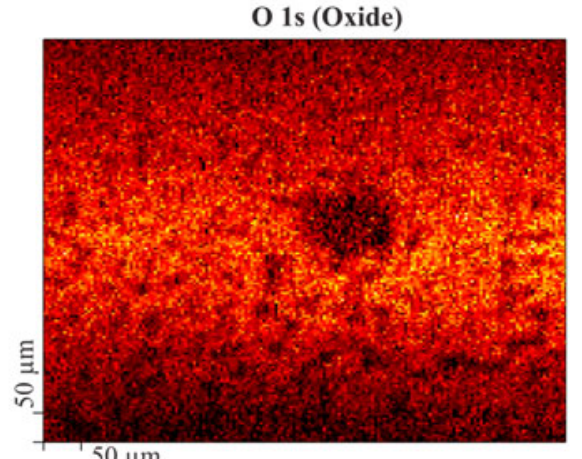

$50 \mu \mathrm{m}$

O 1s (BO)
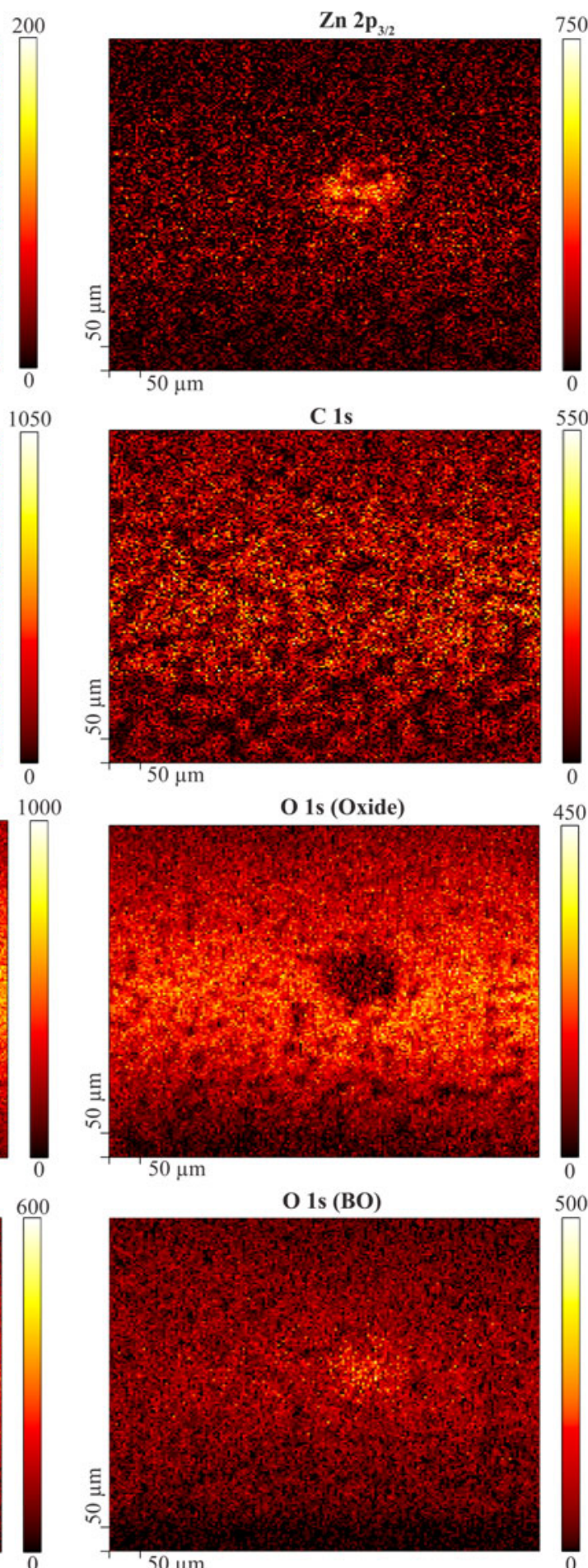

550
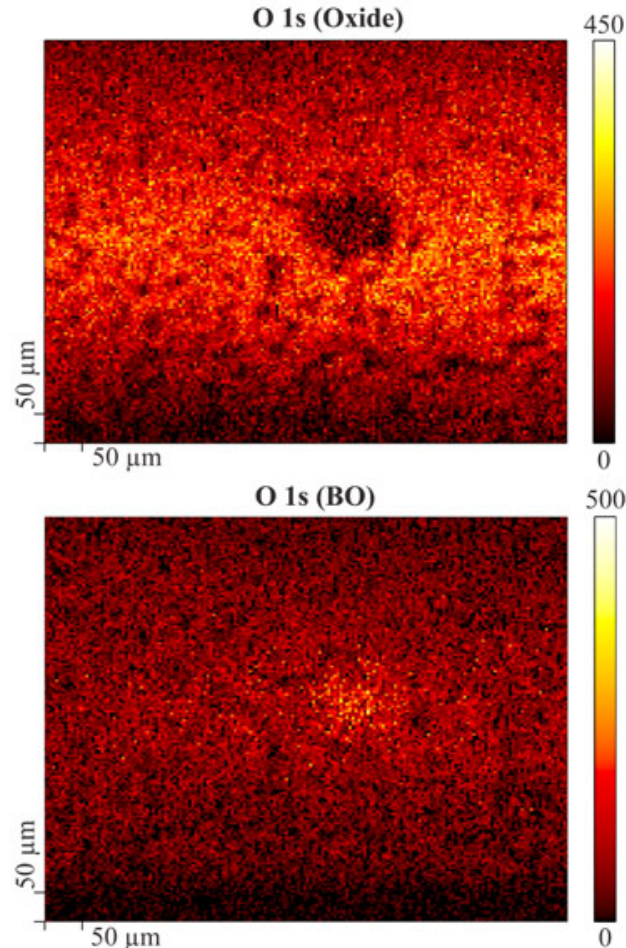

hand, did not show any significant change. Also the $\mathrm{P}$ $2 \mathrm{p}-\mathrm{Zn} 3 \mathrm{~s}$ BE difference, which remains unchanged in the case of zinc pyrophosphates, changes from $6.30 \pm 0.01 \mathrm{eV}$ in the out-of-contact region to $6.35 \pm 0.1 \mathrm{eV}$ in the $5 \mathrm{~N}$ wear track and to $6.42 \pm 0.08 \mathrm{eV}$ in the $7 \mathrm{~N}$ wear track for the case of zinc metaphosphate. The same trend was exhibited by the modified Auger parameter, $\alpha^{\prime}$, which was found to shift towards higher values within the tribotracks for the zinc metaphosphate (see Table 2).

A low-intensity $\mathrm{Si} 2 \mathrm{p}$ peak revealed the transfer of quartz from the ball to the wear track. The values of the $\mathrm{BO} / \mathrm{NBO}$ and the $[\mathrm{O}] /[\mathrm{P}]$ intensity ratios (Table 2 ) might be influenced by the presence of a small $\mathrm{O} 1 \mathrm{~s}$ peak (533.3 $\pm 0.1 \mathrm{eV}$ on sputtered clean quartz, not shown), not 
Table 2 XPS analysis of different chain length polyphosphate discs after tribological testing with quartz balls

\begin{tabular}{lcccccccc}
\hline & \multicolumn{3}{l}{ Zinc metaphosphate } & & \multicolumn{3}{l}{ Zinc pyrophosphate } \\
\cline { 2 - 3 } & Out of contact & $5 \mathrm{~N}$ & $7 \mathrm{~N}$ & & Out of contact & $5 \mathrm{~N}$ & $7 \mathrm{~N}$ \\
\hline BO/NBO intensity ratio & $0.45 \pm 0.03$ & $0.37 \pm 0.05$ & $0.30 \pm 0.05$ & & $0.20 \pm 0.01$ & $0.21 \pm 0.03$ & $0.24 \pm 0.01$ \\
$\mathrm{P} 2 \mathrm{p}-\mathrm{Zn}$ 3s BE difference $(\mathrm{eV})$ & $6.30 \pm 0.01$ & $6.3_{5} \pm 0.1$ & $6.42 \pm 0.08$ & & $6.75 \pm 0.01$ & $6.76 \pm 0.03$ & $6.78 \pm 0.03$ \\
{$[\mathrm{P}] /[\mathrm{Zn}]$ Intensity ratio } & $1.8 \pm 0.1$ & $1.8 \pm 0.1$ & $1.9 \pm 0.1$ & & $1.1 \pm 0.1$ & $1.1 \pm 0.2$ & $1.1 \pm 0.1$ \\
{$[\mathrm{O}] /[\mathrm{P}]$ intensity ratio } & $3.5 \pm 0.1$ & $3.4 \pm 0.1$ & $3.7 \pm 0.2$ & & $3.7 \pm 0.2$ & $3.6 \pm 0.4$ & $4.0 \pm 0.1$ \\
Modified Auger parameter $(\mathrm{eV})$ & $2008.71 \pm 0.06$ & $2008.8_{6} \pm 0.16$ & $2009.18 \pm 0.06$ & & $2009.19 \pm 0.07$ & $2009.11 \pm 0.06$ & $2009.17 \pm 0.09$ \\
\hline
\end{tabular}

For each composition the table shows the values obtained analyzing inside the 5 wear track $(5 \mathrm{~N})$, inside the $7 \mathrm{~N}$ wear track $(7 \mathrm{~N})$ and outside the wear track (out of contact)

easy to discriminate from the NBO and BO peaks. As in the case of the steel-versus-polyphosphates tribo-pairs, the [P]/ $[\mathrm{Zn}]$ intensity ratio did not show any relevant change in the tribostressed areas (Table 2).

\subsubsection{Quartz-Versus-Zinc Polyphosphate Tribo-Pair: XPS Analysis of the Quartz Balls}

The high-resolution spectra for the quartz ball after a tribological test against a zinc pyrophosphate disc at $7 \mathrm{~N}$ are shown in Fig. 7 and the corresponding chemical-state maps and optical image can be found in Figs. 8 and 2d, respectively. As described before for the steel balls, the spectra were acquired in the center, at the border and outside of the contact area. Also on the quartz balls the phosphorus $2 \mathrm{p}$, zinc $3 \mathrm{~s}$ and zinc $2 \mathrm{p}_{3 / 2}$ signals were present inside the contact area, indicating the presence of a glassy transfer film. The Si 2 p peak, found at $103.9 \pm 0.1 \mathrm{eV}$, was almost completely attenuated by the presence of the transfer film. The $\mathrm{O} 1 \mathrm{~s}$ peak, present in the out-of-contact spectrum, can be assigned to quartz (see Fig. 7). Conversely, in the first two points where the polyphosphate transfer film is present, the $\mathrm{O}$ 1s peak was curve fitted with two components $\mathrm{BO}$ and NBO (533.7 eV and $532.2 \mathrm{eV}$ ) although a superimposition with a low-intensity quartz peak cannot be excluded. For this reason it was not possible to convert the O $1 \mathrm{~s}$ map into a chemical-state map, as for the steel balls. However, the $\mathrm{P} 2 \mathrm{p}, \mathrm{Zn} 2 \mathrm{p}_{3 / 2}$, and $\mathrm{Si} 2 \mathrm{p}$ maps in Fig. 8, together with the high-resolution spectra described above, show the presence of an adhesive polyphosphate transfer film over the entire contact area.

As in the case of steel, the films appear to be thicker at the border than in the center of the contact area because the $\mathrm{Si} 2 \mathrm{p}$ peak is less attenuated in the central region.

\section{Discussion}

In the following paragraphs the effect of chain-length and of the presence of iron oxide on the tribochemical reactions and on the formation and functionality of the transfer film will be analyzed. Finally the discussion of this simplified system will be broadened to a comparison with the tribochemistry of ZnDTPs.

\subsection{Tribochemical Reaction of Depolymerization}

The depolymerization reaction of zinc polyphosphates in the presence of iron oxide was first proposed by Martin [16]. The presence of shorter chain lengths inside the tribotracks compared to the non-contact regions was also previously observed [5, 8]. In our previous study [13] it was shown that zinc metaphosphate is depolymerized against steel under sliding conditions. In the present investigation, two more compositions with shorter chain lengths are examined and compared to the case of zinc metaphosphate. A full characterization of these samples and a method for discriminating different-chain-length polyphosphates by XPS can be found in [22]. It has been shown that the combined use of the BO/NBO intensity ratio, the $\mathrm{Zn} 3 \mathrm{~s}-\mathrm{P} 2 \mathrm{p}_{3 / 2}$ difference, the modified Auger parameter and the valence-band region, when available, allows the determination of the sample average chainlength. For this reason, in this paper, we examined not only the $\mathrm{BO} / \mathrm{NBO}$ intensity ratio and the $\mathrm{Zn} 3 \mathrm{~s}-\mathrm{P} 2 \mathrm{p}_{3 / 2}$ difference but also the modified Auger parameter (Table 1) and valence band region (Fig. 5).

\subsubsection{Effect of the Chain-Length}

The change in average chain-length, $n$, of the samples before and after tribological tests against steel balls can be monitored on the $\mathrm{BO} / \mathrm{NBO}$ versus $\mathrm{Zn} 3 \mathrm{~s}-\mathrm{P} 2 \mathrm{p}_{3 / 2}$ graph in Fig. 9a. The $\mathrm{Zn} 3 \mathrm{~s}-\mathrm{P} 2 \mathrm{p}_{3 / 2}$ difference has been used to calculate the average " $n$ " because it is less affected by the presence of contamination than the $\mathrm{BO} / \mathrm{NBO}$ ratio, and therefore more suitable for tribological samples. For the case of metaphosphate, $\mathrm{n}$ is reduced from 13 to 5 following tribological stress, from 3.9 to 2.4 in the case of polyphosphate $_{1.5}$, and remains almost constant in the case of pyrophosphate (from 2.0 to 1.9). Uncertainties in the use of this method are strongly dependent on composition, 
Fig. 7 Small-area XPS on the contact, border and non-contact areas of the quartz ball after tribological testing (at $7 \mathrm{~N}$ normal load) with a zinc pyrophosphate disc
Fig. 8 i-XPS on the contact area of the quartz ball after tribological testing (at $5 \mathrm{~N}$ normal load) with a zinc pyrophosphate disc

\section{Quartz ball after tribotest vs. zinc pyrophosphate}
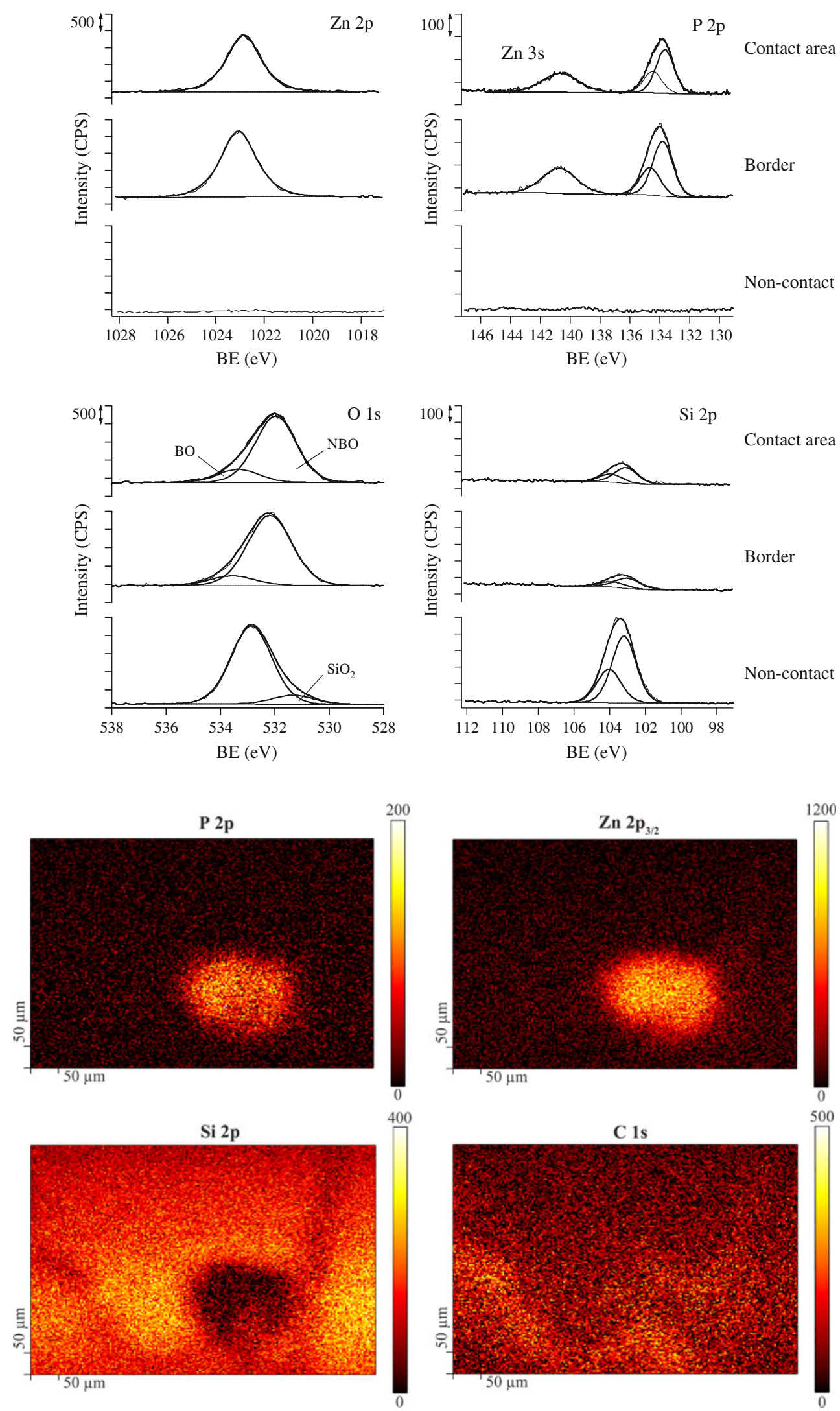

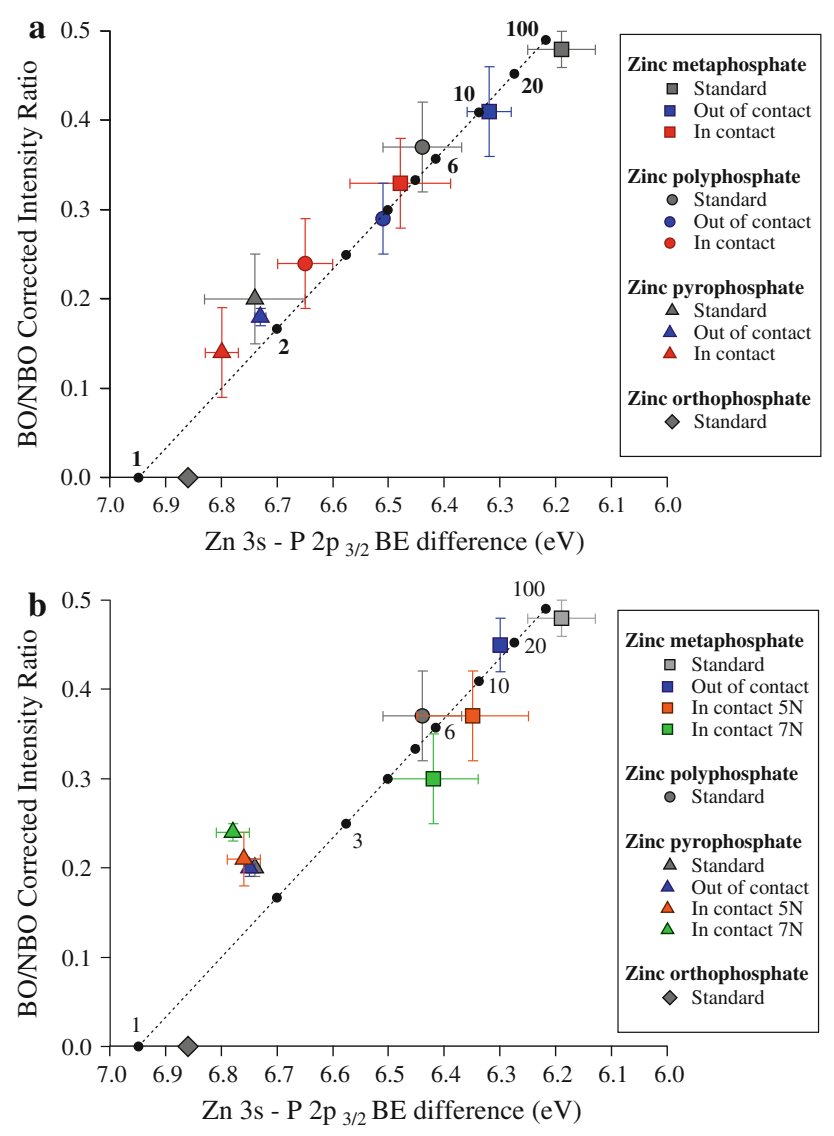

Fig. 9 BO/NBO ratio versus $\mathrm{Zn} 3 \mathrm{~s}-\mathrm{P} 2 \mathrm{p}_{3 / 2}$ BE difference of zinc meta-, poly-, and pyrophosphate discs after tribotesting verus steel balls (a), and of zinc meta- and pyrophosphate discs after tribotesting versus quartz balls (b)

because the correlation between the $\mathrm{Zn} 3 \mathrm{~s}-\mathrm{P} 2 \mathrm{p}_{3 / 2}$ and the $\mathrm{BO} / \mathrm{NBO}$ is exponential: for a $\mathrm{Zn} 3 \mathrm{~s}-\mathrm{P} 2 \mathrm{p}_{3 / 2}$ of $6.32 \pm 0.04$ (zinc metaphosphate in the out-of-contact region) $n$ can lie in between 19 and 8 , while for a $\mathrm{Zn} 3 \mathrm{~s}-\mathrm{P}$ $2 \mathrm{p}_{3 / 2}$ of $6.8 \pm 0.1$ (zinc pyrophosphate after tribological stress) $\mathrm{n}$ is included between 1.1 and 2.0. The trend is confirmed by the values of the modified Auger parameter that are shifting towards higher values in the tribostressed area. A further demonstration of the tribochemical reaction is the shift in the P $3 \mathrm{~s}$ peak in the valence band. As an example, the case of metaphosphate, where the shift is $2.5 \mathrm{eV}$, is reported in Fig. 4.

The activation energy for the depolymerization reaction is provided by the tribological stress. The longer phosphate chain lengths are stabilized by a delocalization of the electrons involved in the covalent bond. The bond length increases with increasing chain-length and, as a result, the $\mathrm{P}-\mathrm{O}-\mathrm{P}$ bond can be more easily broken by the effect of shear stress. In fact the average chain-length of metaphosphate is halved by the tribological stress, while in the case of the pyrophosphate $\mathrm{n}$ remains almost unchanged.

\subsubsection{Role of Iron}

It has been shown that iron oxide can react at low temperatures with zinc polyphosphates in the presence of high pressure and shear stress. The use of an inert material, in this case quartz, as a counterpart in tribological tests can clarify the effect of pressure and shear stress on the tribochemistry of zinc polyphosphates.

The BO/NBO versus $\mathrm{Zn} 3 \mathrm{~s}-\mathrm{P} 2 \mathrm{p}_{3 / 2}$ graph in Fig. 9b shows that in the tribological stressed regions the $\mathrm{BO} / \mathrm{NBO}$ ratios are affected by the presence of the transferred quartz that cannot be resolved in the $\mathrm{O} 1 \mathrm{~s}$ spectrum: the data points measured inside the tribotracks, in fact, are not lying on the line which describes the variation of the average chain-length $\mathrm{n}$ for zinc polyphosphates [22]. Also in this case we used the $\mathrm{Zn} 3 \mathrm{~s}-\mathrm{P} 2 \mathrm{p}_{3 / 2}$ difference to estimate $n$. While in the test with the steel balls the composition in the tribotracks was not dependent on the applied load, in the tests with the quartz balls a correlation of composition with load was found. In the case of zinc metaphosphate the average chain-length varies from 14 in the out-of-contact region to 9 for the $5 \mathrm{~N}$ wear track and 6 in the $7 \mathrm{~N}$ wear track. This is confirmed by the values of the modified Auger parameter, which increases by $0.15 \mathrm{eV}$ from the outof-contact region to the $5 \mathrm{~N}$ tracks and by $0.47 \mathrm{eV}$ from the out-of-contact region to the $7 \mathrm{~N}$ tribotrack. The zinc pyrophosphate sample, in contrast, does not show any significant change in composition, $\mathrm{n}$ is 2 for both the outof-contact region and the $5 \mathrm{~N}$ wear track, and 1.9 in the $7 \mathrm{~N}$ wear track. It is evident that pressure and shear stress, in the presence of water (dissolved in the oil or adsorbed on the sample surface), are causing the depolymerization of the long polyphosphate chains.

\subsection{Formation and Functionality of the Transfer Film}

In our previous study, we observed that the glassy transfer film formed on the ball contact area during the tribological test was able to reduce friction and prevent wear [13]. In this work, the effect of the polyphosphate chain-length on the formation and functionality of the transfer film was investigated. The tribological tests showed that the friction coefficient for all the steel-vs.-zinc-polyphosphate tribopairs was always lower than the case of steel versus steel. The friction coefficient shows a trend towards lower values for the lower chain lengths. The wear coefficient on the ball also shows the same trend with composition. A polyphosphate transfer film was found after each test, regardless of the polyphosphate chain-length. The steel-versus-zincpyrophosphate tribo-pair shows the lowest wear coefficient and an example of the corresponding transfer film is shown in Fig. 6. In ex situ analysis, the pyrophosphate transfer film appeared analogous to those formed by the other 
polyphosphates: the only difference was the size of the flattened area due to the worn volume being lower. The process of transfer-film formation is dynamic and part of the transfer film could have been lost during the rinsing step, which is necessary for the analysis. In situ approaches to tribology are still in their infancy, but some interesting results on dry friction have been published by Scharf and Singer [26]. Monitoring the transfer films of diamond-like nanocomposites on sapphire, many third-body processes could be identified, such as thickening, thinning, and loss of transfer film [26]. It has been also observed that wear in the center of the transfer film indicates the beginning of the thinning process [26]. In our experiments, it was often the case that both the images and the small-area XPS spectra showed that the transfer film was thinner in the center than in the rest of the contact area. This suggests that a similar dynamic behavior may characterize the transfer film of polyphosphate glasses on steel. The reasons for the different behavior with the different polyphosphate chain lengths are likely to be found in the different mechanical and rheological properties of the transfer-film material. The transfer film is formed by wear particles that are detached from the polyphosphate disc and their properties could be very different from those of the bulk materials. Size, shape, and structure of the particles will influence their rheological behavior. For example, the ability of the particles to form a 'compact' layer under the effect of normal load and shear stress, also called 'cohesion' [27, 28], will determine if the behavior of the transfer film will be solid- or fluidlike [29]. In fact, all attempts to use phosphate powders as anti-wear additives have been unable to reproduce the antiwear behavior of ZnDTPs $[21,30]$. The same transfer film could also show a completely different behavior depending on the geometry of the contact, for example, or on the load or temperature. A satisfactory method for the determination of such properties has not yet been developed. Even the use of techniques such as nanoindentation would disturb the investigated layer [27]. It is now commonly accepted that third-body behavior governs friction and wear in dry contacts [27, 28, 31], and those same phenomena have also been found to play an important role in boundary lubrication. For this reason, the development of new techinques for in situ tribological measurements is necessary to shed light into boundary lubrication wear mechanisms.

Many previous publications on ZnDTP have hypothesized that the formation of mixed iron and zinc polyphosphate, as a consequence of the reaction of iron oxide with zinc polyphosphates, can promote the formation and adhesion of the polyphosphate tribofilm on the steel surface $[3,32,33]$. The quartz balls have been analyzed after the tribotests, in order to ascertain the ability of zinc polyphosphates to form adhesive transfer films on an inert material. A transfer film was found on the quartz balls for all the chain-length polyphosphates, suggesting that the adhesion of the transfer film can also take place on materials that do not contain iron. The formation of phosphosilicate compounds has been documented at high temperature by Massiot et al. [34]. The $\mathrm{Si} 2 \mathrm{p}$ signal in a Si$\mathrm{O}-\mathrm{P}$ bond has been reported in an XPS spectrum, shifted $1 \mathrm{eV}$ towards lower BE from the $\mathrm{Si}-\mathrm{O}-\mathrm{Si}$ signal, found at $103.7 \mathrm{eV}$ [34]. A typical Si 2p spectrum measured in a zinc metaphosphate wear track after sliding against quartz is reported in Fig. 10, in comparison with the same region acquired on the clean ball before the tribotest. The two spectra are very similar and no evidence for the formation of $\mathrm{Si}-\mathrm{O}-\mathrm{P}$ bonds can be found. Quartz detached as a consequence of wear and brittle fracture of the ball is transferred and embedded into the polyphosphate discs, but does not appear to react with the substrate. However, a chemical interaction through the formation of $\mathrm{Si}-\mathrm{O}-\mathrm{P}$ bonds, at the interface between quartz and the polyphosphate transfer film cannot be completely ruled out.

\subsection{Insights in the Tribochemistry of ZnDTPs}

The importance of tribochemical reactions and their influence on the composition of ZnDTP tribofilms is already well known. While it is generally accepted that there is no correlation between the tribofilm thickness and wear [35], there is no agreement on whether the tribofilm anti-wear efficiency benefits from the presence of short- or long-chain phosphates. The composition of the tribofilm was found to be dependent on the applied load: Heuberger et al. [5] observed that at higher contact pressures, thicker, tougher films of shorter polyphosphates were formed, which exhibited higher shear resistance, resulting in lower dimensional wear coefficients. The friction force was also found to correlate with the composition of the anti-wear film: the thicker the film, the longer the phosphate chains and the higher the measured friction coefficient [4].

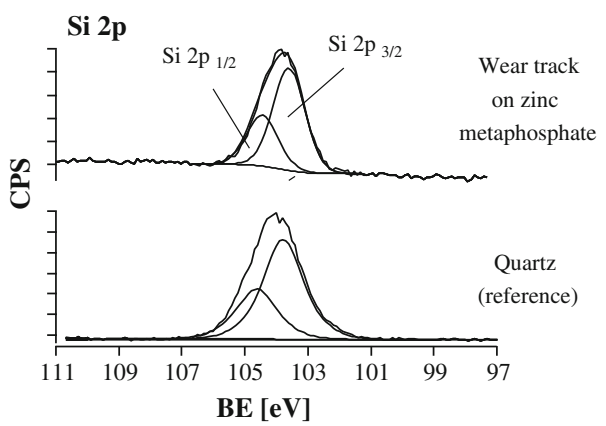

Fig. 10 High-resolution XP-Si $2 p$ spectra acquired on a clean quartz ball in comparison with the $\mathrm{Si} 2 \mathrm{p}$ spectrum acquired inside of the wear track on the zinc metaphosphate disc after tribological testing with a quartz ball at $7 \mathrm{~N}$ normal load 
In the system investigated here, short-chain-length polyphosphates show lower coefficients of friction and wear than the long chain-length polyphosphates in accord with [4, 5].

The experimental data show that indeed the hypothesized reaction of depolimerization is taking place and is certainly contributing to the friction and wear reduction. However, this reaction cannot explain the low wear coefficients of short-chain-length polyphosphates, which do not react with iron oxide. Therefore, in this system, the "digestion" of iron oxide cannot be considered as the main mechanism of wear reduction. In the tribofilms formed in the presence of $\mathrm{ZnDTP}$, the depolymerization reaction is also taking place, influencing the composition of the tribofilm and, as a consequence, its anti-wear properties: where the shear stress and pressure are high, the polyphosphates are depolymerized, even in the absence of iron oxide, by hydrolysis with the water potentially present in the oil, giving rise to a harder, tougher film of short-chainlength polyphosphates with a higher wear resistance. These results support the hypothesis that the tribochemical reactions in the film are indeed contributing to the anti-wear performance of the tribofilm.

As for the mechanical properties of polyphosphate glasses, for a long time there has been no agreement on this topic because of the lack of experimental data on the pure compounds. Recently it has been observed that the structural strength of these glasses is increasing with the degree of connectivity in the glass [30, 36-39]. Baikova et.al. investigated four different phosphate glasses and found that there is a linear dependence of the Young modulus on the total bonding energy per unit volume of the glass [38, 40]. The total bonding energy, $U_{\mathrm{m}}$, is calculated using the most commonly used approach of Makashima and Mackenzie [40], based on the atomic packing density of the glass and the dissociation energies of the oxides. If we calculate $U_{\mathrm{m}}$ for zinc metaphosphate and zinc pyrophosphate, we obtain 3.4 and $3.9 \mathrm{kcal} / \mathrm{cm}^{3}$, respectively, and therefore we can predict an increase in the Young modulus value when going from long to short chain-lengths. The same trend would be obtained when using the approach of Inaba et al. [39]: in their calculations, these authors take into account the presence of $\mathrm{P}=\mathrm{O}$ bonds, which do not contribute to the network stiffness.

Unfortunately, as already mentioned in the previous paragraph, the presence of high load and shear stress will dramatically change the structure of the polyphosphates and, as a consequence, their mechanical properties [30]. If formed under a high load, we can hypothesize an increase in the atomic packing density of the glass [41] that would result in an increase of $U_{\mathrm{m}}$ and, most probably, in the Young modulus. In fact, the comparison between synthesized polyphosphates and ZnDTP tribofilms with the same degree of cross-linking showed an enhancement in the Young's modulus by a factor of 3 for the tribological samples [8-10, 30]. In this comparison it also has to be considered that polyphosphate glasses are only a model for the actual tribofilm, which presents a much more heterogeneous composition (for example it can contain sulfides, sulfates and organic phosphates) that could further influence its mechanical and tribochemical properties.

On the other hand, it has been found that the hardness of the tribofilms is comparable to the mean applied pressure in the rubbing contact [20]. We have shown that zinc polyphosphates can change both their composition and their structure under high load and shear stress, which certainly could contribute to the ability of ZnDTP tribofilms to respond to a wide range of tribological conditions.

\section{Conclusions}

From the results presented in this work the following conclusions can be drawn:

- During the sliding tests of steel balls versus zinc polyphosphate discs, a tribochemical depolymerization reaction takes place within the wear tracks of the long chain-lengths polyphosphates, while the composition of the short-chain-length samples remains essentially unchanged after sliding.

- When an inert counter-face (quartz balls) slides against the long-chain-length glasses, the final composition in the wear track is dependent on the applied load: the higher the applied load, the shorter the chain-length in the wear track. The composition of the short chainlength samples remains unchanged.

- The shorter chain-length polyphosphates exhibit lower friction coefficients and wear coefficients compared to the long chain-length samples.

- The formation of a glassy adhesive transfer film on the steel contact area suggests a third-body mechanism with the polyphosphates acting as a solid lubricant. The reasons for the different tribological performance of the different chain lengths can be related to the different mechanical and rheological properties of the materials.

- In the case of ZnDTP tribofilms, the presence of shortchain-length polyphosphates can improve the mechanical and rheological properties of the film, enhancing the anti-wear efficiency. The tribochemical reaction of glass depolymerization contributes to the ZnDTP tribofilms ability to adapt their wear resistance to the amount of load and shear stress they undergo.

Acknowledgments The authors would like to thank the ETH Research Commission for its support of this work. 


\section{References}

1. Pawlak, Z.: Preface. In: Zenon, P. (ed.) Tribology and Interface Engineering Series, pp. v-vii. Elsevier, Amsterdam (2003)

2. Xue, Q., Liu, W.: Tribochemistry and the development of AW and EP oil additives-a review. Lubr. Sci. 7, 81-92 (1994)

3. Spikes, H.: The history and mechanisms of ZDDP. Tribol. Lett. 17, 469-489 (2004)

4. Heuberger, R., Rossi, A., Spencer, N.D.: XPS study of the influence of temperature on ZnDTP tribofilm composition. Tribol. Lett. 25, 185-196 (2007)

5. Heuberger, R., Rossi, A., Spencer, N.D.: Pressure dependence of ZnDTP tribochemical film formation: a combinatorial approach. Tribol. Lett. 28, 209-222 (2007)

6. Piras, F.M., Rossi, A., Spencer, N.D.: Combined in situ (ATR FT-IR) and ex situ (XPS) study of the ZnDTP-iron surface interaction. Tribol. Lett. 15, 181-191 (2003)

7. Eglin, M., Rossi, A., Spencer, N.D.: X-ray photoelectron spectroscopy analysis of tribostressed samples in the presence of ZnDTP: a combinatorial approach. Tribol. Lett. 15, 199-209 (2003)

8. Canning, G.W., Suominen, M.L., Bancroft, G.M., Kasrai, M., Cutler, J.N., De Stasio, G., Gilbert, B.: Spectromicroscopy of tribological films from engine oil additives. Part I. Films from ZDDP's. Tribol. Lett. 6, 159-169 (1999)

9. Najman, M.N., Kasrai, M., Bancroft, G.M.: X-ray absorption spectroscopy and atomic force microscopy of films generated from organosulfur extreme-pressure (EP) oil additives. Tribol. Lett. 14, 225-235 (2003)

10. Zhang, Z., Yamaguchi, E.S., Kasrai, M., Bancroft, G.M.: Tribofilms generated from ZDDP and DDP on steel surfaces: Part 1, growth, wear and morphology. Tribol. Lett. 19, 211-220 (2005)

11. Martin, J.M., Grossiord, C., Le Mogne, T., Bec, S., Tonck, A.: The two-layer structure of Zndtp tribofilms: Part I: AES, XPS and XANES analyses. Tribol. Int. 34, 523-530 (2001)

12. Yin, Z., Kasrai, M., Fuller, M., Bancroft, G.M., Fyfe, K., Tan, K.H.: Application of soft X-ray absorption spectroscopy in chemical characterization of antiwear films generated by ZDDP Part I: the effects of physical parameters. Wear 202, 172-191 (1997)

13. Crobu, M., Rossi, A., Mangolini, F., Spencer, N.D.: Tribochemistry of bulk zinc metaphosphate glasses. Tribol. Lett. 39, 121-134 (2010)

14. Minfray, C., Le Mogne, T., Lubrecht, A.A., Martin, J.M.: Experimental simulation of chemical reactions between ZDDP tribofilms and steel surfaces during friction processes. Tribol. Lett. 21, 67-78 (2006)

15. Pearson, R.G.: Chemical hardness. Wiley, New York (1997)

16. Martin, J.: Antiwear mechanisms of zinc dithiophosphate: a chemical hardness approach. Tribol. Lett. 6, 1-8 (1999)

17. Minfray, C., Le Mogne, T., Martin, J.-M., Onodera, T., Nara, S., Takahashi, S., Tsuboi, H., Koyama, M., Endou, A., Takaba, H., Kubo, M., Del Carpio, C.A., Miyamoto, A.: Experimental and molecular dynamics simulations of tribochemical reactions with ZDDP: zinc phosphate-iron oxide reaction. Tribol. Trans. 51, 589-601 (2008)

18. Minfray, C., Martin, J.M., Esnouf, C., Le Mogne, T., Kersting, R., Hagenhoff, B.: A multi-technique approach of tribofilm characterization. Thin Solid Films 477, 272-277 (2004)

19. Nicholls, M.A., Bancroft, G.M., Norton, P.R., Kasrai, M., De Stasio, G., Frazer, B.H., Wiese, L.M.: Chemomechanical properties of antiwear films using X-ray absorption microscopy and nanoindentation techniques. Tribol. Lett. 17, 245-259 (2004)

20. Bec, S., Tonck, A., Georges, J.M., Coy, R.C., Bell, J.C., Roper, G.W.: Relationship between mechanical properties and structures of zinc dithiophosphate anti-wear films. Proc. R. Soc. Lond. A 455, 4181-4203 (1999)
21. Gauvin, M., Dassenoy, F., Belin, M., Minfray, C., Guerret-Piecourt, C., Bec, S., Martin, J.M., Montagnac, G., Reynard, B.: Boundary lubrication by pure crystalline zinc orthophosphate powder in oil. Tribol. Lett. 31, 139-148 (2008)

22. Crobu, M., Rossi, A., Mangolini, F., Spencer, N.: Chain-lengthidentification strategy in zinc polyphosphate glasses by means of XPS and ToF-SIMS. Anal. Bioanal. Chem. 403, 1415-1432 (2012)

23. Brow, R.K.: An XPS study of oxygen bonding in zinc phosphate and zinc borophosphate glasses. J. Non-Cryst. Solids 194, 267-273 (1996)

24. Brow, R.K.: Review: the structure of simple phosphate glasses. J. Non-Cryst. Solids 263-264, 1-28 (2000)

25. Smith, G.C.: Evaluation of a simple correction for the hydrocarbon contamination layer in quantitative surface analysis by XPS. J. Electron. Spectrosc. 148, 21-28 (2005)

26. Scharf, T.W., Singer, I.L.: Monitoring transfer films and friction instabilities with in situ Raman tribometry. Tribol. Lett. 14, 3-8 (2003)

27. Descartes, S., Berthier, Y.: Rheology and flows of solid third bodies: background and application to an MoS1.6 coating. Wear 252, 546-556 (2002)

28. Iordanoff, I., Berthier, Y., Descartes, S., Heshmat, H.: A review of recent approaches for modeling solid third bodies. J. Tribol. 124, 725-735 (2002)

29. Hou, K., Kalousek, J., Magel, E.: Rheological model of solid layer in rolling contact. Wear 211, 134-140 (1997)

30. Pawlak, Z., Yarlagadda, P.K.D.V., Frost, R., Hargreaves, D.: The mechanical characteristics of phosphate glasses under high temperature and friction-induced cross-linking processes. Journal of Achievements in Materials and Manufacturing Engineering 37, 458-465 (2009)

31. Singer, I.L.: Mechanics and chemistry of solids in sliding contact. Langmuir 12, 4486-4491 (1996)

32. Gellman, A., Spencer, N.: Surface chemistry in tribology. Proceedings of the Institution of Mechanical Engineers, Part J: Journal of Engineering Tribology 216, 443-461 (2002)

33. Nicholls, M.A., Norton, P.R., Bancroft, G.M., Kasrai, M., Do, T., Frazer, B.H., De Stasio, G.: Nanometer scale chemomechanical characterization of antiwear films. Tribol. Lett. 17, 205-216 (2004)

34. Massiot, P., Centeno, M.A., Carrizosa, I., Odriozola, J.A.: Thermal evolution of sol-gel-obtained phosphosilicate solids (SiPO). J. Non-Cryst. Solids 292, 158-166 (2001)

35. Fuller, M.L.S., Kasrai, M., Bancroft, G.M., Fyfe, K., Tan, K.H.: Solution decomposition of zinc dialkyl dithiophosphate and its effect on antiwear and thermal film formation studied by X-ray absorption spectroscopy. Tribol. Int. 31, 627-644 (1998)

36. Kurkjian, C.R.: Mechanical properties of phosphate glasses. J. Non-Cryst. Solids 263-264, 207-212 (2000)

37. Reis, S.T., Karabulut, M., Day, D.E.: Chemical durability and structure of zinc-iron phosphate glasses. J. Non-Cryst. Solids 292, 150-157 (2001)

38. Baikova, L.G., Pukh, V.P., Fedorov, Y.K., Sinani, A.B., Tikhonova, L.V., Kireenko, M.F.: Mechanical properties of phosphate glasses as a function of the total bonding energy per unit volume of glass. Glass Phys. Chem. 34, 126-131 (2008)

39. Inaba, S., Fujino, S., Morinaga, K.: Young's modulus and compositional parameters of oxide glasses. J. Am. Ceram. Soc. 82, 3501-3507 (1999)

40. Makishima, A., Mackenzie, J.D.: Direct calculation of Young's modulus of glass. J. Non-Cryst. Solids 12, 35-45 (1973)

41. Mackenzie, J.D.: High-pressure effects on oxide glasses: I, densification in rigid state. J. Am. Ceram. Soc. 46, 461-470 (1963) 